\title{
About contributors and the author
}

The author thanks for valuable contributions: Brian Hengesbaugh, partner, Baker \& McKenzie Chicago; Theodore Ling, partner, Baker \& McKenzie Toronto; Christoph Rittweger, partner, Baker \& McKenzie Munich; Prof. Susan Freiwald, Professor of Law, University of San Francisco School of Law; Sarah Jain, Legal Director, Employment, Dolby Laboratories, Inc.; Dr. Ron A. Dolin, Legal Technologist and Fellow at Stanford University; Dr. Sebastian Kraska, Rechtsanwalt, Externer Datenschutzbeauftragter, IITR GmbH; Joshua Glucoft, University of California, Berkeley School of Law, JD Candidate 2014; Diana Francis, Baker \& McKenzie Palo Alto; Emmanuel Fua, Stanford Law School, JD Candidate 2012. The author takes sole responsibility for any errors and omissions.

The author, Lothar Determann, practices and teaches international data privacy, commercial and intellectual property law. He is admitted to practice law in Germany and California, a partner with Baker \& McKenzie LLP in Palo Alto, California, and recognized as one of the top 25 Intellectual Property Attorneys in California by the San Francisco/Los Angeles Daily Journal, listed in the World's 250 Leading Patent and Technology Licensing Practitioners by the Intellectual Asset Management (IAM) Magazine and ranked as a leading lawyer in Chambers USA, Legal 500 USA and California Super Lawyers. Prof. Determann has been a member of the Association of German Public Law Professors since 1999 and he teaches Data Privacy Law, Computer Law and Internet Law at UC Berkeley School of Law (Boalt Hall, since 2004), Hastings College of the Law (since 2010), Freie Universität Berlin (since 1994) and Stanford Law School (since 2011). He has previously authored three books and more than 70 articles and treatise contributions. 